Boise State University

ScholarWorks

Biology Faculty Publications and Presentations

Department of Biological Sciences

$1-1-2019$

\title{
The Role of Antarctica in Biogeographical Reconstruction: A Point of View
}

\author{
Manuel de la Estrella \\ Royal Botanic Gardens \\ Sven Buerki \\ Boise State University \\ Thais Vasconcelos \\ Royal Botanic Gardens \\ Eve J. Lucas \\ Royal Botanic Gardens \\ Félix Forest \\ Royal Botanic Gardens
}




\title{
THE ROLE OF ANTARCTICA IN BIOGEOGRAPHICAL RECONSTRUCTION: A POINT OF VIEW
}

\author{
Manuel de la Estrella, ${ }^{1, *}+$ Sven Buerki, $\neq$ Thais Vasconcelos, ${ }^{*}$ Eve J. Lucas, ${ }^{*}$ and Félix Forest*
}

\begin{abstract}
*Comparative Plant and Fungal Biology Department, Royal Botanic Gardens, Kew, Richmond, Surrey, TW9 3DS, United Kingdom; tDepartamento de Botánica, Ecología y Fisiología Vegetal, Facultad de Ciencias, Campus de Rabanales, Universidad de Córdoba, 14071, Córdoba, Spain; and ‡Department of Biological Sciences, Boise State University, 1910 University Drive, Boise, Idaho 83725, USA
\end{abstract}

\author{
Editor: Susan J. Mazer
}

\begin{abstract}
Premise of research. The opening of the Drake Passage in the Miocene (disconnecting Antarctica and South America and resulting in the establishment of the Circumpolar Current preventing warm waters from the north to reach the polar continent) has led to the formation of the ice sheets and the retreat of the temperate to tropical vegetation that had covered Antarctica for millions of years. With only two current native vascular plant species, Antarctica has been virtually ignored in biogeographical reconstructions and, when considered, only a posteriori invoked as a route of dispersal to reconcile inferred disjunct biogeographical patterns.
\end{abstract}

Methodology. Here, we provide a brief overview of the rich fossil record of Antarctica, further confirming that many plant families were once present on this continent and that the age of a family is mostly not correlated with its presence or absence on the continent. Such evidence indicates a need to develop a paleogeographical model incorporating Antarctica that can be applied to constrain ancestral area reconstructions. We propose such a model and investigate its effects on biogeographical scenarios using the cosmopolitan plant family Myrtaceae (a family with a rich fossil record in Antarctica) as a case study.

Pivotal results. Based on this evidence and previous studies that have shown the importance of Antarctica in the biogeography and evolution of plant lineages, we argue that this region should routinely be included as a predefined area in biogeographical analyses.

Conclusions. A possible paleogeographical model including Antarctica is proposed. It is subdivided into five time slices and spans the last $160 \mathrm{Myr}$. We expect that the formal inclusion of Antarctica in ancestral area reconstructions (using an evidence-based biogeographical model) will open further discussions and research programs assessing the importance of this area in shaping the current temperate and tropical floras and increase the precision of resulting biogeographical patterns.

Keywords: ancestral area reconstruction, biogeography, DEC, glaciations, Gondwana, Southern Hemisphere.

Online enhancements: appendix table and figure.

\section{Introduction}

Our understanding of biodiversity patterns and the distribution of species on the planet have benefited enormously from the development of phylogenetic and statistical approaches applied to reconstruct biogeographical patterns and infer the associated processes underpinning them (Sanmartin et al. 2001). An increased number of new methodologies have been developed, from the study of vicariance and dispersal events (Ronquist 1997; Sanmartin and Ronquist 2004), to parametric approaches (Ree et al. 2005; Ree and Smith 2008; Ree and Sanmartín 2009), Bayesian methods (Sanmartin et al. 2008; Lemey et al. 2009), and more

\footnotetext{
1 Author for correspondence; email: mdelaestrella@gmail.com.
}

Manuscript received February 2018; revised manuscript received June 2018; electronically published November 29, 2018. recently developed tools that allow comparisons of approaches and inclusion of distance and dispersal parameters (Matzke et al. 2014; Matzke 2015; Matzke and Wright 2016; Sukumaran et al. 2016; Van Dam and Matzke 2016). These methods allow the integration of several variables that have either implicitly played an important role in the distribution of species throughout evolutionary time (e.g., plate tectonics, global wind patterns, ocean currents) or provide information on the presence of species in areas where they may not be found today (e.g., fossils, pollen cores).

Notwithstanding these methodological improvements, a key step in the design of any biogeographical analysis remains the definition of areas. Most biogeographical studies define areas in which organisms occur based on past geological events (i.e., the geological criterion) either at a global scale (Buerki et al. 2011) or using more localized partitioning (e.g., island biogeography; Ree and Smith 2008; Bennett and O'Grady 2013; Strijk 
et al. 2014; for further discussion, see Barry Cox 2001; Arias et al. 2011; Buerki et al. 2011; Arias 2017). Other studies circumscribe areas based on the ecological tolerance and current distribution patterns of their group of interest (i.e., areas of endemism; Morrone and Crisci 1995). This approach may be problematic in the sense that different groups may exhibit different distribution patterns and, therefore, resulting area definition may not be comparable across groups (Buerki et al. 2011). If the studied group is relatively narrowly distributed, areas are usually defined by taking into consideration past geological or climatic conditions (Forest et al. 2014; Wang et al. 2014) or based on vegetation types/biomes (e.g., Cardillo et al. 2017). In contrast, when the taxa being studied have a comparatively broader distribution range (i.e., worldwide scale), areas generally refer to major continental units in a similar configuration across studies. Often this will include, at least in part, Africa, Madagascar and the Mascarene Islands (although some studies consider Africa and Madagascar a single area), South and Central America, North America, Eurasia (with the Indian subcontinent sometimes considered independently), Southeast Asia, and the Australia-Pacific region (Buerki et al. 2011, 2013; Calviño et al. 2016; Ruhfel et al. 2016).

Current biogeographical analyses more often focus on presentday distributions, while the role played by ancestral distributions (i.e., extinct lineages currently occurring outside of the range of extant taxa) is generally either ignored in ancestral area reconstructions or considered subsequent to the analysis (but see Nauheimer et al. 2012; Meseguer et al. 2015; Estrella et al. 2017). This situation is particularly acute regarding Antarctica. Although most of Antarctica's surface is currently covered with ice, the continent has a rich vegetation history, comprehensively reviewed by Cantrill and Poole (2012). Antarctica was predominantly ice-free following the Gondwana breakup (ca. $160 \mathrm{Ma}$ ) and was covered by temperate to subtropical forests along its coastal areas until the Pliocene (Swenson and Bremer 1997; Cantrill and Poole 2012). For a time, Antarctica was connected to other major landmasses of Gondwanan origin (Scotese 2004; Müller et al. 2016), and light conditions were more favorable for plant growth, as the continent was at more northern latitudes than it is today (Scotese 2004; Müller et al. 2016). From the Late Cretaceous to middle Eocene, global temperatures were warmer; Antarctica temperatures were assumed to have oscillated around $20^{\circ} \mathrm{C}$, thus being able to sustain tropical/subtropical vegetation (Pross et al. 2012). The role played by this vegetation type has been suggested as being pivotal in shaping the biogeographical patterns observed in many plant groups (Nauheimer et al. 2012; Conran et al. 2015; Givnish et al. 2016a). There is also a rich fossil flora in Antarctica associated with this period (fig. 1).

In general, parametric biogeographical studies dealing with broadly distributed taxa or groups with clear Southern Hemisphere distribution patterns (and of relatively old origin) have investigated biogeographical patterns with only an a posteriori consideration of Antarctica's role (e.g., Cai et al. 2016; CardinalMcTeague et al. 2016; Givnish et al. 2016a, 2016b; Ruhfel et al. 2016). This role is always as a possible dispersal route between South America, Africa, or Australia. There is extensive evidence of the past presence of several plant groups in Antarctica (fig. 1), including several plant lineages now characteristic of tropical regions. Nevertheless, there are a few exceptions. Nauheimer et al.
(2012) studied the evolutionary origin of Araceae and included Antarctica not merely as a dispersal route but as one of the areas within their biogeographical model, although this approach has not been extensively followed. Landis (2017) advocated the application of a paleogeographically informed process to date phylogenies and included Antarctica as one of the continental units in his model. More recently, the evolutionary origin of subfamily Detarioideae of the legume family was investigated using a biogeographical reconstruction model implicitly allowing taxa to be present in Antarctica at relevant time periods (Estrella et al. 2017).

Here, we test whether the inclusion of Antarctica would affect the biogeographical reconstruction of a group for which there is extensive fossil evidence of its presence there, using a recently published phylogenetic study of tribe Myrteae (Myrtaceae; Vasconcelos et al. 2017) as a case study. We also present a brief overview of the fossil record of angiosperms and gymnosperms in Antarctica to further explore the potential role this continent played in shaping current plant distributions. Finally, this overview also demonstrates the implications of considering Antarctica not only as an a posteriori route for dispersal but also as a predefined area in biogeographical analyses. To achieve these goals and further test these hypotheses, a stratified paleogeographical model is proposed and used to constrain parametric biogeographical analyses. Such a model will contribute to the implicit consideration of the role of Antarctica through time in plant biogeography.

\section{Antarctica Vascular Plant Flora: An Overview of the Fossil Record}

The presence of a taxon in the fossil record in any region of the world confirms the occurrence of a particular group there at a given time, while the absence of a group in the fossil record could be either the result of its limited past abundance or caused by other problems linked to the fossilization process itself (Behrensmeyer et al. 2000). The vagaries of fossilization mean, as is generally the case worldwide, a taxonomic bias in the fossil record is also found in Antarctica, with some groups having an abundant fossil record and others being absent (Cantrill and Poole 2012). Furthermore, confirming the presence of a specific group in Antarctica could be largely compromised by the laborious and complicated process of investigating the fossil record on the continent, as only few localities have been explored due to limited accessibility (Cantrill and Poole 2012).

Antarctica was free of permanent ice during the Paleozoic, Mesozoic, and early Paleogene (Cantrill and Poole 2012; Iglesias 2016). During this period, the flora on James Ross Island comprised cycads, conifers, ferns, and angiosperms from the Santa Marta Formation (early-mid Campanian; 83.6-72.1 Ma). The early Cretaceous period was characterized by a global warm climate and polar regions free of permanent ice covers (Francis and Frakes 1993; Zachos et al. 2001; Zachos et al. 2008; Galeotti et al. 2016). Southern Hemisphere forests were dominated by podocarpaceous and araucariaceous gymnosperms, which were accompanied by a lower vegetation of gingkopsids, ferns, and angiosperms (Falcon-Lang and Cantrill 2001; Cantrill and Poole 2012). This was apparently a common condition during that period in the southern polar region (paleolatitude above $60^{\circ} \mathrm{S}$ ), where forests were able to remain evergreen during the longer 


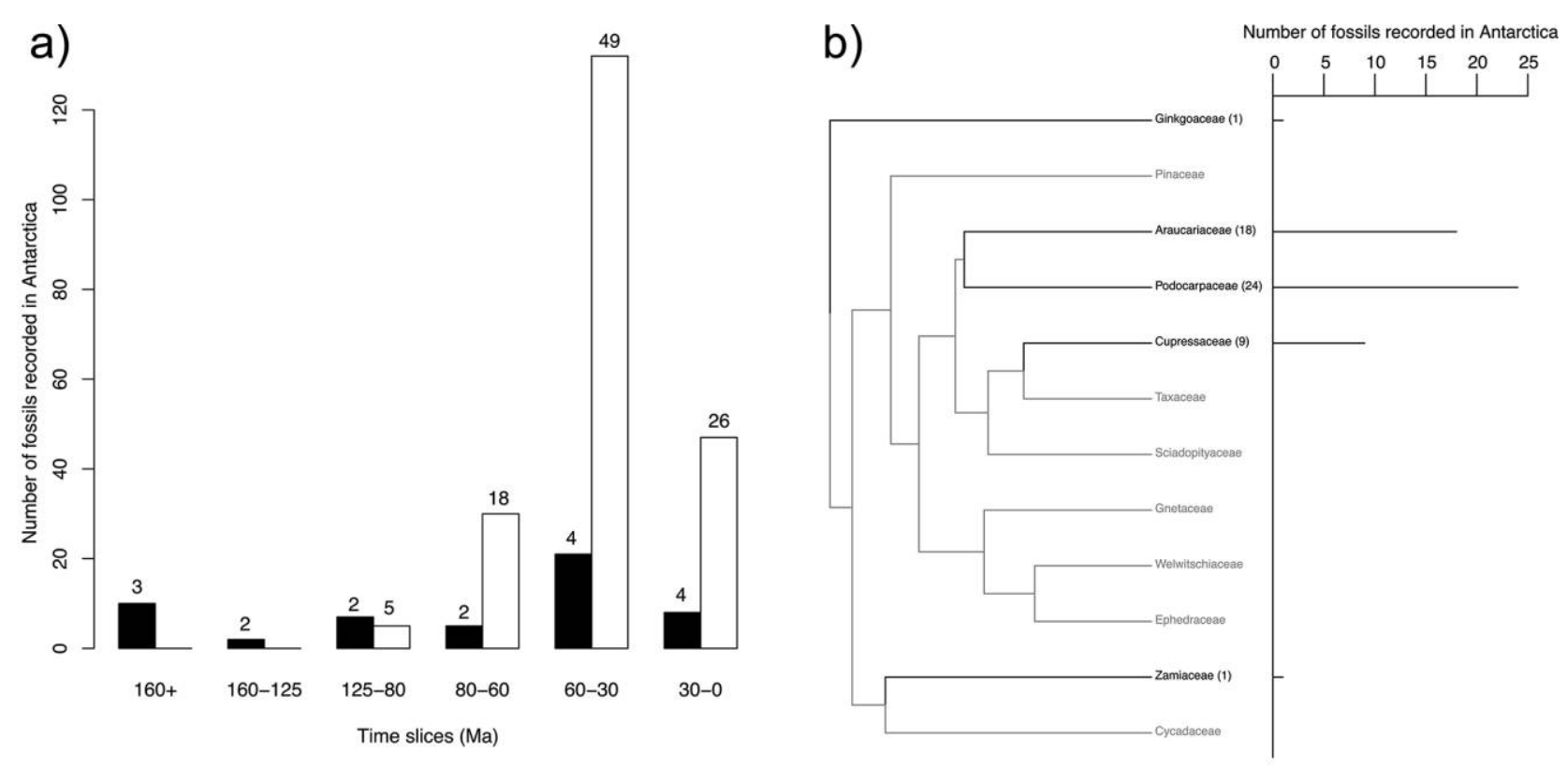

c)

c)
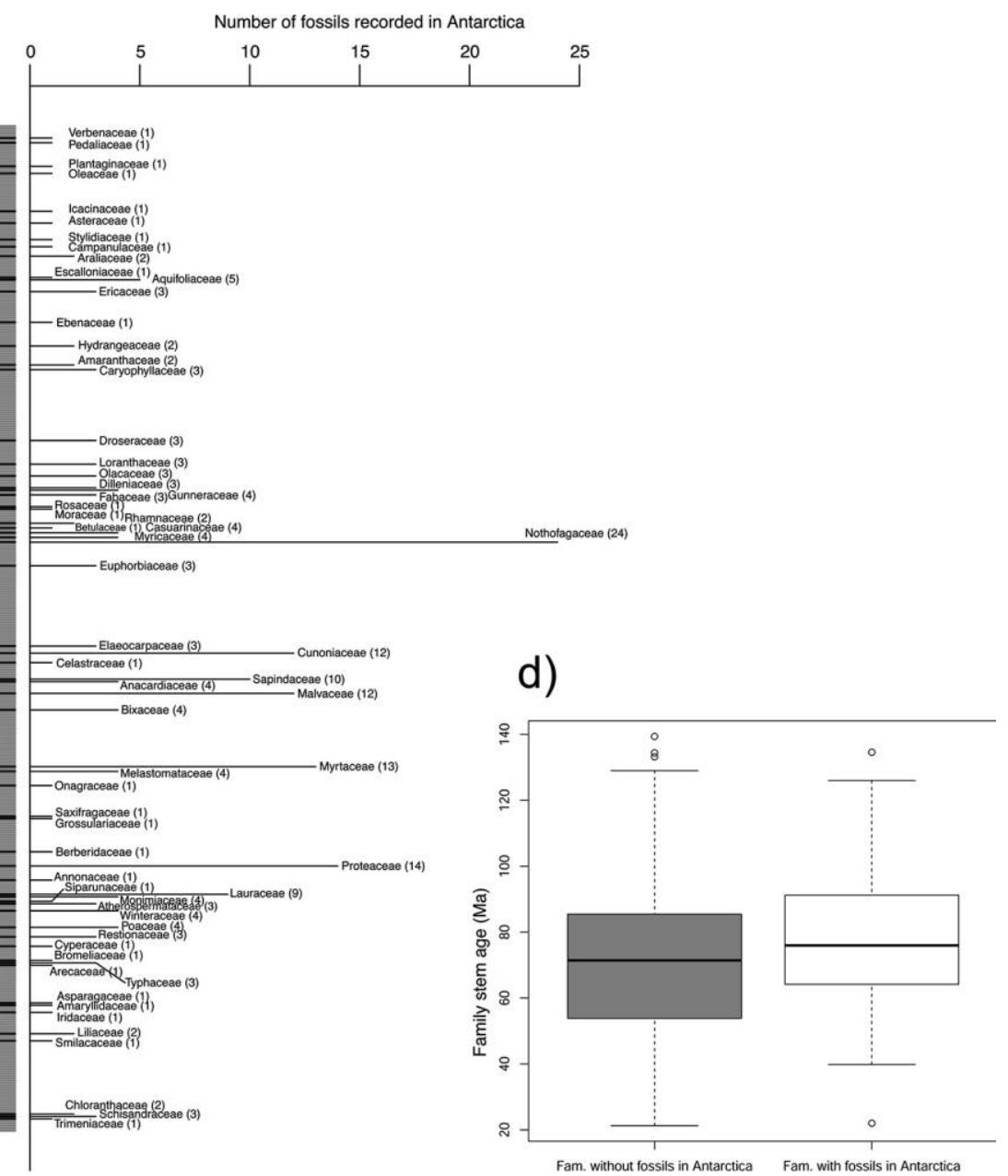

Fig. 1 Antarctica fossil record through geological time. Fossils of gymnosperms (black bars) and angiosperms (white bars) reported from Antarctica along the different time slices proposed in the biogeographical model $(a)$. Number of gymnosperms fossils reported from Antarctica plotted on the gymnosperm phylogeny ( $b$; Forest et al. 2018). Number of angiosperms fossils reported from Antarctica plotted on the angiosperm phylogeny ( $c$; Magallón et al. 2015). Stem age of angiosperm families with and without fossil representatives recorded in Antarctica $(d$; Cantrill and Poole 2012; Magallón et al. 2015). 
and darker (but warm) seasons with high respiration rates (Falcon-Lang and Cantrill 2001; Cantrill and Poole 2012).

There are currently only two known native vascular plants from Antarctica, Colobanthus quitensis (carnation family; Caryophyllaceae) and Deschampsia antarctica (grass family; Poaceae), although if sub-Antarctic islands are considered as part of the continent, this number increases to 261 (Greene and Walton 1975; Govaerts 2001). The taxonomic extent of the fossil record is proof that Antarctica was once covered by a significantly more diverse temperate to subtropical flora (Cantrill and Poole 2012; Pross et al. 2012; Barreda et al. 2015). The first record of fossil plants from Antarctica was a carbonized wood from the South Shetland Islands (Eights 1833), while the first records of angiosperms in Antarctica are pollen records from the early to mid-Albian on James Ross Island (Dettmann and Thomson 1987; Riding and Crame 2002). Since then, 68 extant angiosperm families have been reported in the fossil record of Antarctica (Cantrill and Poole 2012; Behrensmeyer and Turner 2013), with Nothofagaceae, Proteaceae, and Myrtaceae among the most regularly uncovered families (fig. 1).

Antarctica has most probably played a central role in the migration and evolution of angiosperms in southern latitudes during the Early Cretaceous (Cantrill and Poole 2012). At a later stage, angiosperms probably dominated Antarctic ecosystems as they generally do worldwide today (fig. 1 a). For example, leguminous leaves have been reported from King George Island and Seymour Island (Zastawniak et al. 1985; Hunt and Poole 2003; Cantrill and Poole 2012). Birkenmajer and Zastawniak (1986) described a diverse assemblage of dicotyledons from Dufayel Island, including possible Cochlospermaceae, Dilleniaceae, Leguminosae, Sapindaceae, Sterculiaceae, and Verbenaceae (Cantrill and Poole 2012). Many other fossils of different lineages have been found in Antarctica at different geological periods (fig. 1), and some lineages may even have appeared and then diversified from Antarctica, despite now being absent from the continent.

We present an overview of the Antarctic plant (angiosperms and gymnosperms) fossil record as compiled by Cantrill and Poole (2012) as well as fossils in the Fossilworks database (Behrensmeyer and Turner 2013) and examine their phylogenetic coverage and temporal distribution (fig. 1). This exercise does not attempt to be an exhaustive review of the fossil record (for that, see Cantrill and Poole 2012; Behrensmeyer and Turner 2013; and references therein) but is meant to provide an overview of the past flora known from Antarctica, to support a narrative that argues in favor of the incorporation of this area in biogeographical models. During earlier times (fig. 1a), gymnosperms were probably dominant in Antarctica, with most representatives assigned to Araucariaceae and Podocarpaceae (42 of 53 fossils reported; fig. $1 b$ ). There is a remarkable shift in the fossil composition after the appearance of angiosperm lineages (fig. 1a). Flowering plant families represented in the Antarctic fossil record are phylogenetically scattered across the angiosperm Tree of Life (fig. 1c). The prevalence of lineages such as Nothofagaceae, Proteaceae, and Myrtaceae is evident, but also many of today's more temperate lineages, such as Saxifragaceae, previously occurred in Antarctica (fig. 1c). Moreover, there is no temporal structure in the fossil record of Antarctica. Using a dated phylogenetic tree of angiosperms (Magallón et al. 2015), we considered whether the age (i.e., stem age) of families with a pres- ence in the fossil record of Antarctica would be a good surrogate for determining whether Antarctica should be considered a priori when reconstructing biogeographical patterns. We found no evidence for the prevalence of older lineages in Antarctica's paleoflora.

The known Antarctic fossil record underlines the importance of the use of Antarctica as an area in biogeographical models. The absence of a given family from the fossil record of Antarctica cannot itself justify disregarding it as a plausible area in relevant time periods. The phylogenetic distribution of the fossil record of Antarctica and the age of the families represented in it, compared with those that are not, clearly demonstrates the need to consider the continent independently of the organisms being studied (fig. $1 c, 1 d$ ). This overview of the gymnosperm and angiosperm fossil record in Antarctica illustrates further the need for a new stratified paleogeographical model for ancestral area reconstruction.

\section{Proposal for a Biogeographical Model including Antarctica}

The paleogeographical model proposed here is adapted from Buerki et al. $(2011,2013)$ and includes Antarctica for the relevant time periods (fig. 2). The model is divided into five time slices based on the model proposed by Buerki et al. (2013): (1) Early to mid-Cretaceous (160-125 Ma), reflecting the period leading to the Pangea breakup, when the world's flora was dominated by nonangiosperm taxa; (2) Mid-Cretaceous to Late Cretaceous (125-80 Ma), when the world was dominated by gymnosperms and ferns, with the eminent appearance and rise of angiosperms; (3) Late Cretaceous to Early Paleocene (80$60 \mathrm{Ma})$; (4) Mid-Paleocene to Late Eocene (60-30 Ma); and (5) Oligocene (30 Ma) to present (fig. 2). The area connection matrices were developed following Buerki et al. (2013), by assigning a dispersal probability of 1.0 to areas directly connected, of 0.5 to areas not directly connected but with a small barrier between them, and of 0.01 for areas with large oceanic barriers between them.

The Pangea supercontinent cleaved into two subunits, Laurasia and Gondwana, separated by the Tethys Sea. Antarctica was a central subunit in Gondwana, in contact with all other subcontinents (fig. 2; for more details, see Scotese 2004; Müller et al. 2016). Antarctica remained connected to New Zealand, Australia, and South America until the late Cretaceous (fig. 2; biogeographical implications are explored in Sanmartin and Ronquist 2004; Buerki et al. 2011, 2013). Antarctica played a central role in the evolution of Southern Hemisphere biodiversity, allowing a connection between Australia and South America until the Eocene (fig. 2; Scotese 2004; Müller et al. 2016). The landmass connection between Antarctica and Patagonia (South America) through the Antarctic Peninsula vanished with the opening of the Drake Passage in the Miocene (ca. $16 \mathrm{Ma}$ Cantrill and Poole 2012), allowing development of the marine Circumpolar Current. This current isolated Antarctica from warm sea currents coming from the north and initiated the first Antarctic glaciation (Zachos et al. 2001, 2008; Scotese 2004; Cantrill and Poole 2012; Galeotti et al. 2016). The new biogeographical model, including area connection matrices for each time slice, can be visualized in figure 2 (see also the appendix, available online). 
(a) Time slice A. 160-125 Ma

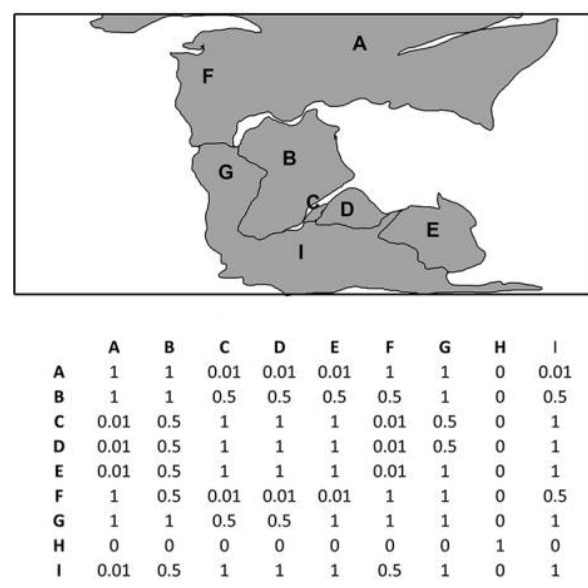

(c) Time slice C. 80-60 Ma
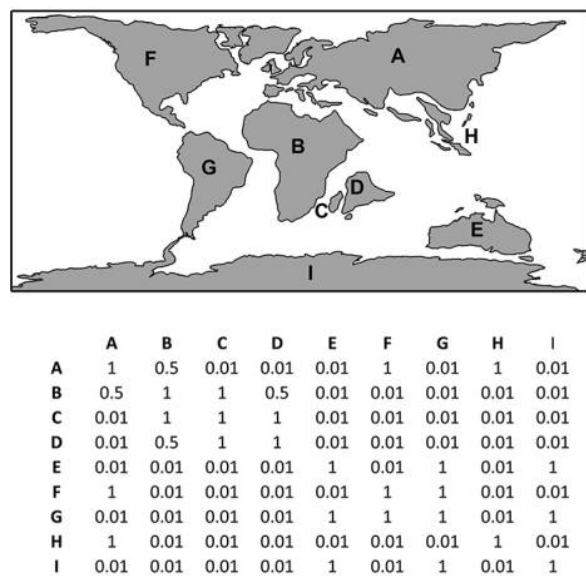

(e) Time slice E. 30-0 Ma
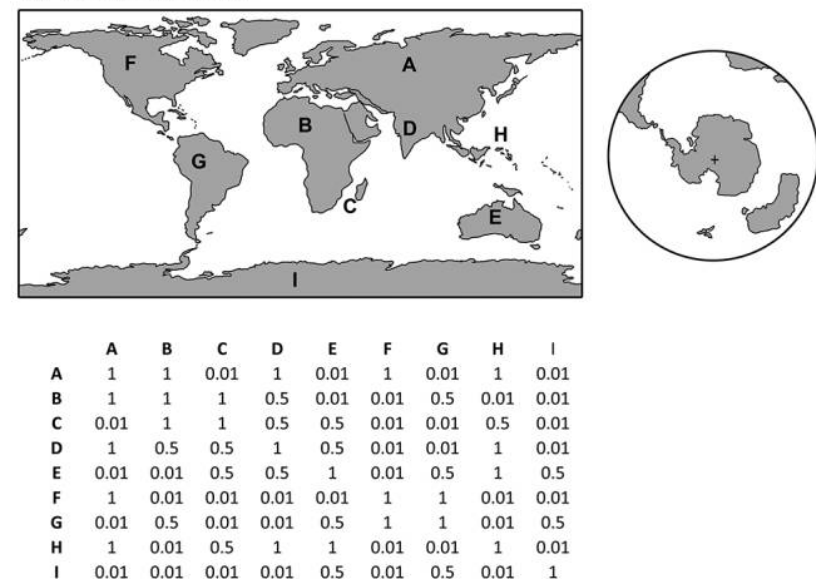

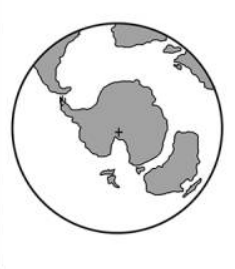

(b) Time slice B. 125-80 Ma
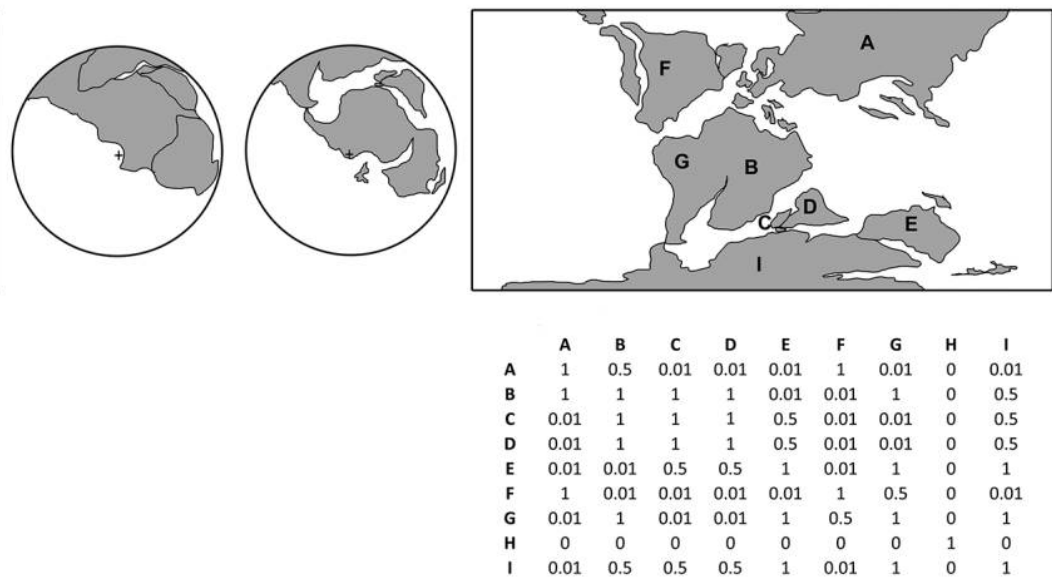

(d) Time slice D. 60-30 Ma

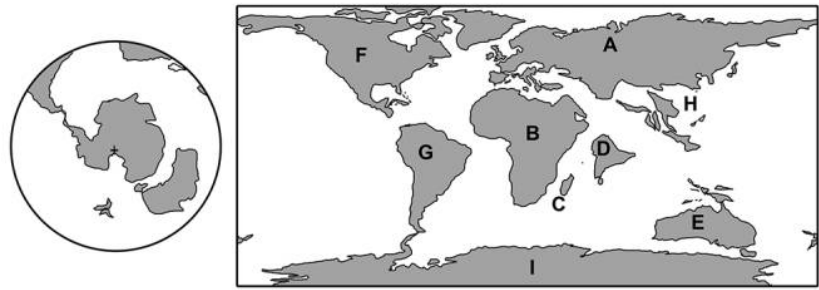

(f) Biogeographical regions for the model

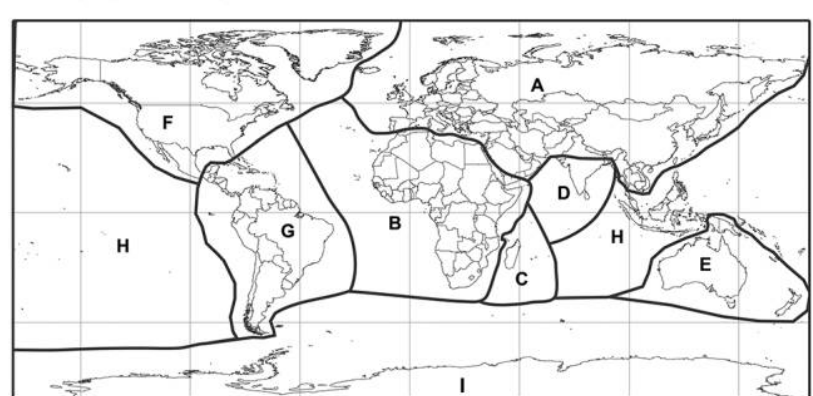

Fig. 2 Biogeographical model. Paleogeographical model proposed, with five time slices reflecting the probability of area connectivity through time; the position of Antarctica with respect to the South Pole is highlighted $(a-e)$. Biogeographical regions proposed in the model following Buerki et al. (2011, 2013): A = Eurasia, B = Africa, C = Madagascar (including the Comoro Islands and Mascarene Islands), D = India (including Sri Lanka), E = Australasia (including Australia, New Guinea, New Caledonia, and New Zealand), F = North America, G = South America (including Central America and the West Indies), $\mathrm{H}=$ Southeast Asia (including India, the Malaysian Peninsula, the Philippines, Sumatra, Borneo, and the Inner Banda Arc as well as the Pacific Islands such as Hawaii), I = Antarctica and sub-Antarctic islands $(f)$. 

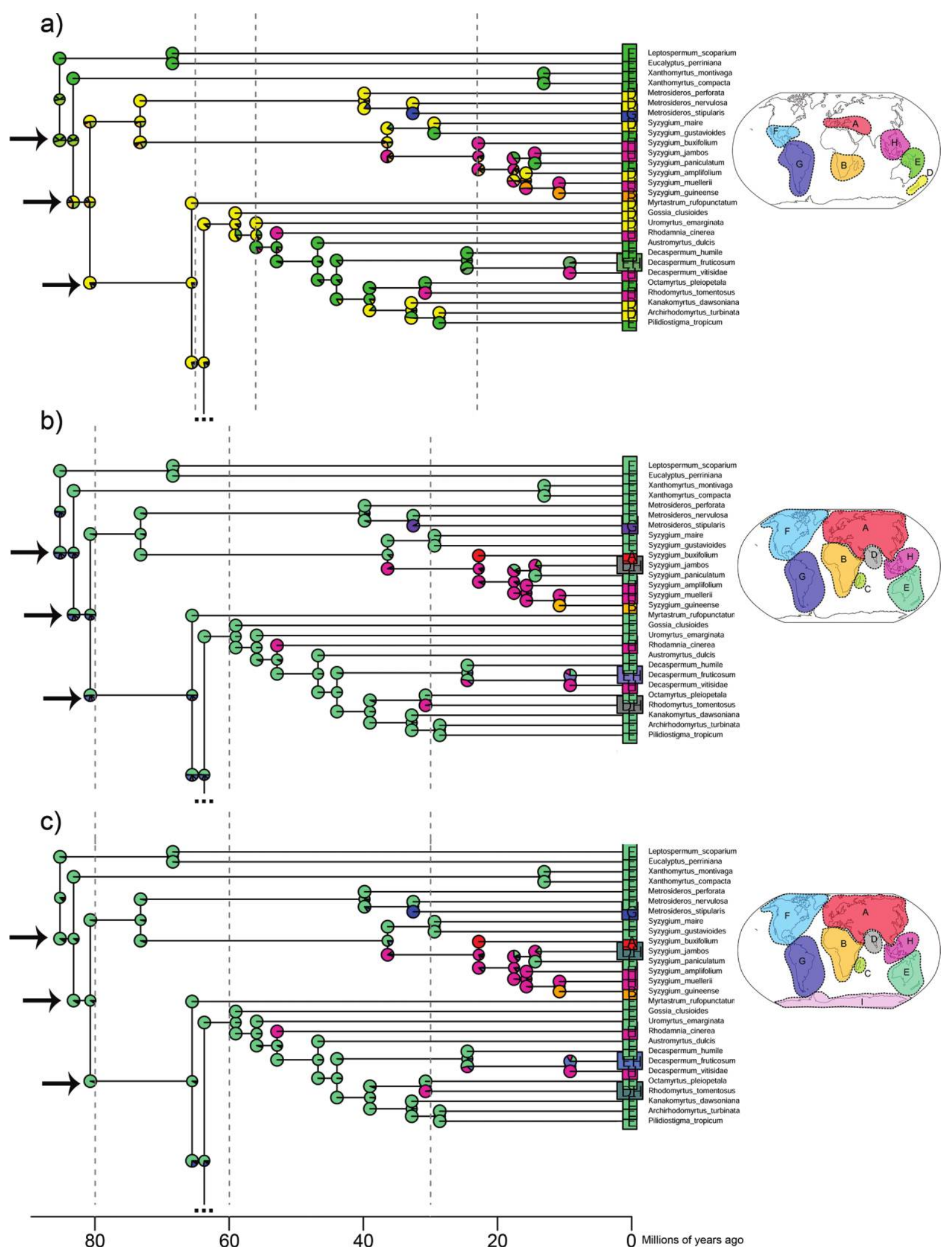

Fig. 3 Biogeographical reconstruction of tribe Myrteae (details of early-diverging lineages). Original results from Vasconcelos et al. (2017; a). Biogeographic reconstruction with the areas/connectivity matrices excluding Antarctica $(b)$. Biogeographic reconstruction with the model proposed here, including Antarctica; arrows point to deep nodes in which reconstructed area probabilities are more significantly divergent between scenarios $(c)$. The ancestral range estimation for Myrteae was performed using the dispersal-extinction-cladogenesis $\mathrm{j}(\mathrm{DEC} \mathrm{j})$ model in the BioGeoBears R package (Matzke 2014; Matzke et al. 2015). The dispersal-extinction-cladogenesis (DEC) model as implemented in BioGeoBears evaluates maximum-likelihood parameters for events involving range expansion and extinction and for cladogenetic events involving sympatry and vicariance. DECj models have been shown to be significantly better than DEC models for island groups and for intercontinental distributions (Matzke et al. 2014). Inferred ancestors were allowed to occupy all possible areas, and dispersal probabilities between pairs of areas were specified following the proposed model for the different time slices (fig. 2). 


\section{Accounting for Antarctica: Challenges and a Myrtaceae Case Study}

The assignment of fossils to specific lineages or nodes onto a phylogeny as calibration points for the estimation of divergence times is rarely performed unequivocally. One way to increase confidence in the phylogenetic position of a fossil is to use an approach combining the reconstruction of morphological features shared between extant and extinct species along a constrained phylogenetic framework (see Barreda et al. 2015). However, not all plant groups allow such an approach because of limited morphological features available from the fossil record. For example, pollen fossils of Sapindaceae have been found in Antarctica, but these are mostly associated to the type B pollen category (as defined by Müller and Leenhouts 1976). This pollen type is scattered across different genera in the phylogenetic tree of Sapindaceae, greatly reducing the utility of the character in the calibration (Buerki et al. 2009). The incomplete fossil record is also an inherent issue.

Tribe Myrteae (Myrtaceae) represents a good example of how different fossil placement in calibration of phylogenetic trees can affect results (Vasconcelos et al. 2017). In addition, the oldest fossilized representatives of the family are from Antarctica and are represented by wood and leaf remains (Poole et al. 2003; Cantrill and Poole 2012). Therefore, this group is a pertinent clade in which to test whether direct inclusion of Antarctica in the biogeographical model would result in different biogeographical scenarios compared with models that do not account for it. We use the dispersal-extinction-cladogenesis (DEC) model, as implemented in the $\mathrm{R}$ package BioGeoBears (Ree and Smith 2008; Matzke 2015), to explore the potentially divergent results. Figure $3 a$ shows the first diverging lineages within tribe Myrteae following the approach and parameters defined in Vasconcelos et al. (2017). The results of the biogeographical model proposed here are shown in figure $3 b$ and $3 c$, excluding and including Antarctica, respectively; the exclusion of Antarctica follows the methodology of Buerki et al. (2011). The three nodes most affected in the three analyses are identified by arrows. In the original analysis of Vasconcelos et al. (2017), no single area is assigned to the deeper nodes (identified by arrows; fig. 3), with a combination of areas being the most likely. This would suggest a likely origin of the family in Gondwana and explain its predominance in the Southern Hemisphere today. Uncertainty at these three deeper nodes remains (fig. $3 b$ ) when the biogeographical patterns are reconstructed using the biogeographical model of Buerki et al. (2011), where the area definition and dispersal matrix differ slightly from those implemented in Vasconcelos et al. (2017). The Antarctica-inclusive biogeographical model (fig. 3c) presented here recovers a single predefined area, that is, Australia/New Zealand, as the most likely ancestral area on these three deep nodes. This suggests that tribe Myrteae originated in this region, which was directly connected to Antarctica $80 \mathrm{Ma}$ (fig. 2c), where the oldest macrofossil of this tribe was discovered.

The most recent biogeographical reconstruction of Myrtaceae, based on a wide and representative species sample, was undertaken by Thornhill et al. (2015). This Myrtaceae-focused analysis returned an unequivocal ancestral area of Australia for Myrtaceae and an ancestral area of tribe Myrteae shared between Australia and New Zealand. The results of Thornhill et al. (2015) match those recovered using the Antarctica-inclusive model presented here. This suggests that as well as increasing biogeographical precision in the Myrteae-focused analysis of Vasconcelos et al. (2017), the Antarctica-inclusive model has increased biogeographical precision at all nodes, in line with an analysis based on a much broader sample of taxa. Caution is necessary, however, as the biogeographical methods used in the two studies differ, with Thornhill et al. (2015) optimizing modern geographic locations of extant taxa over a dated phylogeny using maximum parsimony and not implementing the DEC model.

\section{Conclusions}

Antarctica still has many secrets to reveal, from deep ice cores that will allow us to understand past climatic shifts (e.g., Jouzel et al. 2007) or new fossil discoveries from the paleoflora (Cantrill and Poole 2012). An early-diverging lineage of Asteraceae was recently discovered (Barreda et al. 2015), which completely changed our understanding of the evolution and biogeography of the largest/most diverse angiosperm family and pushed its previously assumed origin back by $20 \mathrm{Ma}$. More discoveries of this type are likely in the future, as the exploration of Antarctica's fossil record continues. We expect that the formal inclusion of Antarctica in ancestral area reconstructions using an evidence-based biogeographical model will initiate further discussion about the role of Antarctica in shaping the distribution of plants, particularly in the Southern Hemisphere, and give the least well-explored continent of the world the importance it deserves.

\section{Acknowledgments}

We thank Luis Palazzesi for his suggestions regarding the fossil record and biogeographical models and Salvador Arias, Susana Magallón, and two anonymous reviewers for comments on the manuscript. M. de la Estrella was funded by the European Union's Horizon 2020 Research and Innovation Programme under the Marie Skłodowska-Curie grant agreement 659152 (GLDAFRICA).

\section{Literature Cited}

Arias JS 2017 An event model for phylogenetic biogeography using explicitly geographical ranges. L Biogeogr 44:2225-2235.

Arias JS, CA Szumik, PA Goloboff 2011 Spatial analysis of vicariance: a method for using direct geographical information in historical biogeography. Cladistics 27:617-628.
Barreda VD, L Palazzesi, MC Telleria, EB Olivero, JI Raine, F Forest 2015 Early evolution of the angiosperm clade Asteraceae in the cretaceous of Antarctica. Proc Natl Acad Sci USA 112:10989-10994.

Barry Cox C 2001 The biogeographic regions reconsidered. J Biogeogr 28:511-523. 
Behrensmeyer AK, SM Kidwell, RA Gastaldo 2000 Taphonomy and paleobiology. Paleobiology 26:103-147.

Behrensmeyer AK, A Turner 2013 Taxonomic occurrences of Suidae recorded in the paleobiology database. Fossilworks. http://fossilworks .org.

Bennett GM, PM O'Grady 2013 Historical biogeography and ecological opportunity in the adaptive radiation of native Hawaiian leafhoppers (Cicadellidae: Nesophrosyne). L Biogeogr 40:1512-1523.

Birkenmajer K, E Zastawniak 1986 Plant remains of the Dufayel Island Group (early Tertiary?), King George Island, South Shetland Islands (West Antarctica). Acta Palaeobot 26:33-53.

Buerki S, DS Devey, MW Callmander, PB Phillipson, F Forest 2013 Spatio-temporal history of the endemic genera of Madagascar. Bot LLinn Soc 171:304-329.

Buerki S, F Forest, P Acevedo-Rodríguez, MW Callmander, JAA Nylander, M Harrington, I Sanmartín, P Küpfer, N Alvarez 2009 Plastid and nuclear DNA markers reveal intricate relationships at subfamilial and tribal levels in the soapberry family (Sapindaceae). Mol Phylogenet Evol 51:238-258.

Buerki S, F Forest, N Alvarez, JA Nylander, N Arrigo, I Sanmartín 2011 An evaluation of new parsimony-based versus parametric inference methods in biogeography: a case study using the globally distributed plant family Sapindaceae. I Biogeogr 38:531-550.

Cai L, Z Xi, K Peterson, C Rushworth, J Beaulieu, CC Davis 2016 Phylogeny of Elatinaceae and the tropical Gondwanan origin of the Centroplacaceae (Malpighiaceae, Elatinaceae) clade. PLoS ONE 11:e0161881.

Calviño CI, FE Teruel, SR Downie 2016 The role of the southern hemisphere in the evolutionary history of Apiaceae, a mostly North temperate plant family. I Biogeogr 43:398-409.

Cantrill DJ, I Poole 2012 The vegetation of Antarctica through geological time. Cambridge University Press, Cambridge.

Cardillo M, PH Weston, ZKM Reynolds, PM Olde, AR Mast, EM Lemmon, AR Lemmon, L Bromham 2017 The phylogeny and biogeography of Hakea (Proteaceae) reveals the role of biome shifts in a continental plant radiation. Evolution 71:1928-1943.

Cardinal-McTeague WM, KJ Sytsma, JC Hall 2016 Biogeography and diversification of Brassicales: a 103 million year tale. $\underline{\mathrm{Mol} \mathrm{Phy}-}$ logenet Evol 99:204-224.

Conran JG, JM Bannister, DE Lee, RJ Carpenter, EM Kennedy, T Reichgelt, RE Fordyce 2015 An update of monocot macrofossil data from New Zealand and Australia. Bot I Linn Soc 178:394-420.

Dettmann ME, MRA Thomson 1987 Cretaceous palynomorphs from the James Ross island area, Antarctica: a pilot study. Br Antarct Surv Bull 77:13-59.

Eights J 1833 Description of a new crustaceous animal found on the shores of the South Shetland islands. Trans Albany Inst 2:183-201.

Estrella M, F Forest, JJ Wieringa, M Fougère-Danezan, A Bruneau 2017 Insights on the evolutionary origin of Detarioideae, a clade of ecologically dominant tropical African trees. New Phytol 214: 1722-1735.

Falcon-Lang HJ, DJ Cantrill 2001 Leaf phenology of some midCretaceous polar forests, Alexander Island, Antarctica. Geological Magazine 138:39-52.

Forest F, P Goldblatt, JC Manning, D Baker, JF Colville, DS Devey, S Jose, M Kaye, S Buerki 2014 Pollinator shifts as triggers of speciation in painted petal Irises (Lapeirousia: Iridaceae). Ann Bot 113: 357-371.

Forest F, J Moat, E Baloch, NA Brummitt, SP Bachman, S Ickert-Bond, PM Hollingsworth, et al 2018 Gymnosperms on the EDGE. $\underline{\text { Sci Rep }}$ 8:6053.

Francis JE, LA Frakes 1993 Cretaceous climates. Pages 17-30 in PV Wright, ed. Sedimentology review. Vol 1. Blackwell Scientific, London. Galeotti S, R DeConto, T Naish, P Stocchi, F Florindo, M Pagani, P Barrett, et al 2016 Antarctic ice sheet variability across the EoceneOligocene boundary climate transition. Science 352:76-80.
Givnish TJ, D Spalink, M Ames, SP Lyon, SJ Hunter, A Zuluaga, A Doucette, et al 2016a Orchid historical biogeography, diversification, Antarctica and the paradox of orchid dispersal. I Biogeogr 43:1905-1916.

Givnish TJ, A Zuluaga, I Marques, VKY Lam, MS Gomez, WJD Iles, M Ames, et al $2016 b$ Phylogenomics and historical biogeography of the monocot order Liliales: out of Australia and through Antarctica. Cladistics 32:581-605.

Govaerts R 2001 How many species of seed plants are there? Taxon 50:1085-1090.

Greene SW, DWH Walton 1975 An annotated check list of the subAntarctic and Antarctic vascular flora. Polar Record 17:473-484.

Hunt RJ, I Poole 2003 Paleogene West Antarctic climate and vegetation history in light of new data from King George Island. In: SL Wing, PD Gingerich, B Schmitz, E Thomas, eds. Causes and consequences of globally warm climates in the Early Paleogene. Boulder, Colorado, Geological Society of America, 395-412. (Geological Society of America Special Paper, 369).

Iglesias A 2016 New upper Cretaceous (Campanian) flora from James Ross Island, Antarctica. Ameghiniana 53:358-374.

Jouzel J, V Masson-Delmotte, O Cattani, G Dreyfus, S Falourd, G Hoffmann, B Minster, et al 2007 Orbital and millennial Antarctic climate variability over the past 800,000 years. Science 317:793-796.

Landis MJ 2017 Biogeographic dating of speciation times using paleogeographically informed processes. Syst Biol 66:128-144.

Lemey P, A Rambaut, AJ Drummond, MA Suchard 2009 Bayesian phylogeography finds its roots. PLoS Comput Biol 5:e1000520.

Magallón S, S Gómez-Acevedo, LL Sánchez-Reyes, T HernándezHernández 2015 A metacalibrated time-tree documents the early rise of flowering plant phylogenetic diversity. New Phytol 207:437-453.

Matzke NJ 2015 Model selection in historical biogeography reveals that founder-event speciation is a crucial process in island clades. Syst Biol 64:167.

Matzke NJ, PM Shih, CA Kerfeld 2014 Bayesian analysis of congruence of core genes in Prochlorococcus and Synechococcus and implications on horizontal gene transfer. PLoS ONE 9:e85103.

Matzke NJ, A Wright 2016 Inferring node dates from tip dates in fossil Canidae: the importance of tree priors. Biol Lett 12:20160328.

Meseguer AS, JM Lobo, R Ree, DJ Beerling, I Sanmartin 2015 Integrating fossils, phylogenies, and niche models into biogeography to reveal ancient evolutionary history: the case of Hypericum (Hypericaceae). Syst Biol 64:215-232.

Morrone JJ, JV Crisci 1995 Historical biogeography: introduction to methods. Annu Rev Ecol Syst 26:373-401.

Müller J, PW Leenhouts 1976 A general survey of pollen types in Sapindaceae in relation to taxonomy. Pages 407-445 in IK Ferguson, J Müller, eds. The evolutionary significance of the exine. Academic Press, London.

Müller RD, M Seton, S Zahirovic, SE Williams, KJ Matthews, NM Wright, GE Shephard, et al 2016 Ocean basin evolution and globalscale plate reorganization events since Pangea breakup. Annu Rev Earth Planet Sci 44:107-138.

Nauheimer L, D Metzler, SS Renner 2012 Global history of the ancient monocot family Araceae inferred with models accounting for past continental positions and previous ranges based on fossils. New Phytol 195:938-950.

Poole I, AMW Mennega, DJ Cantrill 2003 Valdivian ecosystems in the late Cretaceous and early Tertiary of Antarctica: further evidence from Myrtaceous and Eucryphiaceous fossil wood. Rev Palaeobot Palynol 124:9-27.

Pross J, L Contreras, PK Bijl, DR Greenwood, SM Bohaty, S Schouten, JA Bendle, et al 2012 Persistent near-tropical warmth on the Antarctic continent during the early Eocene Epoch. Nature 488:73-77.

Ree RH, BR Moore, CO Webb, MJ Donoghue 2005 A likelihood framework for inferring the evolution of geographic range on phylogenetic trees. Evolution 59:2299-2311. 
Ree RH, I Sanmartín 2009 Prospects and challenges for parametric models in historical biogeographical inference. I Biogeogr 36:12111220.

Ree RH, SA Smith 2008 Maximum likelihood inference of geographic range evolution by dispersal, local extinction, and cladogenesis. Syst Biol 57:4-14.

Riding JB, JA Crame 2002 Aptian to Coniacian (early-late Cretaceous) palynostratigraphy of the Gustav group, James Ross basin, Antarctica. Cretaceous Res 23:739-760.

Ronquist F 1997 Dispersal-vicariance analysis: a new approach to the quantification of historical biogeography. Syst Biol 46:195-203.

Ruhfel BR, CP Bove, CT Philbrick, CC Davis 2016 Dispersal largely explains the gondwanan distribution of the ancient tropical clusioid plant clade. Am I Bot 103:1117-1128.

Sanmartin I, H Enghoff, F Ronquist 2001 Patterns of animal dispersal, vicariance and diversification in the Holarctic. Biol I Linn Soc 73: 345-390.

Sanmartin I, F Ronquist 2004 Southern Hemisphere biogeography inferred by event-based models: plant versus animal patterns. Syst Biol 53:216-243.

Sanmartin I, P Van der Mark, F Ronquist 2008 Inferring dispersal: a bayesian approach to phylogeny-based island biogeography, with special reference to the Canary Islands. I Biogeogr 35:428-449.

Scotese CR 2004 A continental drift flipbook. I Geol 112:729-741.

Strijk JS, RE Bone, C Thébaud, S Buerki, PW Fritsch, TR Hodkinson, D Strasberg 2014 Timing and tempo of evolutionary diversification in a biodiversity hotspot: Primulaceae on Indian Ocean islands. I Biogeogr 41:810-822.

Sukumaran J, EP Economo, LL Knowles 2016 Machine learning biogeographic processes from biotic patterns: a new trait-dependent dis- persal and diversification model with model choice by simulationtrained discriminant analysis. Syst Biol 65:525-545.

Swenson U, K Bremer 1997 Pacific biogeography of the Asteraceae genus Abrotanella (Senecioneae, Blennospermatinae). Syst Bot 22: 493-508.

Thornhill AH, SY Ho, C Külheim, MD Crisp 2015 Interpreting the modern distribution of Myrtaceae using a dated molecular phylogeny. Mol Phylogenet Evol 93:29-43.

Van Dam MH, NJ Matzke 2016 Evaluating the influence of connectivity and distance on biogeographical patterns in the southwestern deserts of North America. I Biogeogr 43:1514-1532.

Vasconcelos TNC, CEB Proença, B Ahmad, DS Aguilar, R Aguilar, BS Amorim, K Campbell, et al 2017 Myrteae phylogeny, calibration, biogeography and diversification patterns: increased understanding in the most species rich tribe of Myrtaceae. Mol Phylogenet Evol 109:113-137.

Wang CB, T Wang, YJ Su 2014 Phylogeography of Cephalotaxus oliveri (Cephalotaxaceae) in relation to habitat heterogeneity, physical barriers and the uplift of the Yungui plateau. Mol Phylogenet Evol 80:205-216.

Zachos J, M Pagani, L Sloan, E Thomas, K Billups 2001 Trends, rhythms, and aberrations in global climate $65 \mathrm{ma}$ to present. Science 292:686-693.

Zachos JC, GR Dickens, RE Zeebe 2008 An early cenozoic perspective on greenhouse warming and carbon-cycle dynamics. Nature 451:279-283.

Zastawniak E, R Wrona, A Gazdzicki, K Birkenmajer 1985 Plant remains from the top part of the point Hennequin group (Upper Oligocene), King George Island (South Shetland Islands, Antarctica). Stud Geol Pol 81:143-164. 